\title{
Leitura: uma necessidade para alunos e professores
} Reading: a need for students and teachers

Andréa Pelegrini Pedagoga. Professora da rede municipal de Educação da cidade de São Paulo apelegrini@sme.prefeitura.sp.gov.br

\section{Resumo}

Este trabalho apresenta o resultado de uma intensa pesquisa teórica sobre a importância da leitura no processo de alfabetização. Durante esse processo, algumas leituras foram substituídas e outras feitas à exaustão, tais como Délia Lerner e Paulo Freire, com vistas à apropriação de suas ideias. Tem por objetivo servir de auxílio ao aprimoramento da atuação pedagógica de professores-alfabetizadores na escola, com o fomento de práticas que valorizem a vivência dos alunos, que enfatizem a necessidade de se estabelecer vínculos entre leitura escolar e prática social da leitura e, principalmente, que tendem a erradicar da escola a visão de leitura apenas como decifração do código linguístico.

Palavras-chave: Alfabetização. Cultura. Leitura. Livros. Professor-Alfabetizador.

\section{Abstract}

This paper presents the result of an intense theoretical research on the importance of reading in the literacy process. During this process, some readings were abandoned, replaced and others made to exhaustion, such as Delia Lerner and Paulo Freire, with a view to appropriating their ideas. It aims to serve as an aid to improve the performance of teachers teaching literacy in school, with the encouragement of practices that enhance the experience of students, emphasizing the need to establish links between school reading and social practice of reading and especially they tend to eradicate school reading vision just as deciphering the language code.

Key words: Books. Culture. Literacy. Literacy Teacher. Reading. 


\section{Introdução}

“Ler é entrar em outros mundos possíveis. [. . .] é tirar carta de cidadania no mundo da cultura escrita [.. .]". (LERNER, 2002, p. 73)

Muitas mudanças ocorreram nos métodos de ensino da leitura e da escrita nas salas de alfabetização. A leitura é hoje vista como um conjunto indissociável que envolve a decifração do código linguístico e a compreensão do que é lido. Este artigo analisa a importância da leitura nos processos de alfabetização, apontando a relevância do uso de textos que, além de significativos para os alunos, favoreçam um tipo de leitura que os conduza a uma postura atuante na sociedade e estimulem, no professor, a busca de ser um leitor proficiente.

O estudo aqui realizado visa contribuir para o aprimoramento da atuação pedagógica de professores-alfabetizadores, oferecendo subsídios teóricos que indiquem os benefícios que uma leitura consciente e crítica pode gerar nos alunos. Oferece ainda uma visão sócio-política da leitura como instrumento de inserção social, posto que o conhecimento por ela gerado concede ao indivíduo o poder de atuação sobre o mundo, transformando-o e transformando a si próprio.

Justifica-se tal empreendimento por diversas necessidades: de fomento de uma leitura como prática rotineira nas escolas e fora delas; de erradicação de uma visão equivocada de que a leitura realizada nas escolas difere daquela que ocorre fora de seus muros e de que primeiro aprende-se a ler para depois ler de fato, ou seja, primeiro decifra-se o código e só depois é que se passa a compreender o que se lê, como se fossem momentos distintos do aprendizado; e de utilização de textos e palavras já incorporados pela criança na oralidade para fins de alfabetização.

\section{Ler é mais do que juntar letras}

A linguagem expressa de forma escrita utiliza-se de sinais, denominados signos linguísticos (ou códigos), que são representações da linguagem falada. $\mathrm{O}$ ato de ler foi encarado, durante muito tempo, como mera decifração destes signos, 
atribuindo-se pouco valor ou deixando-se para um segundo momento o ato de compreender e interpretar aquilo que se lia. Atualmente, possui-se uma visão teórica completamente diferente do ato de ler. Tem-se por leitura: compreender aquilo que se lê, interagir com o texto lido, atribuir-lhe valor e assimilar seu conteúdo com o conhecimento que já se possui do assunto, concomitantemente ao ato da decifração do código linguístico, pois é somente com a compreensão e apropriação do que é lido que o indivíduo é capaz de atuar no mundo.

Uma leitura eficaz promove uma articulação do leitor com o mundo que o cerca, já que é a partir da habilidade da leitura que o indivíduo é capaz de se inserir no mundo dos letrados, e é sabido o grande poder gerado pelo domínio da leitura e da escrita. Não seria nenhum exagero falar que o mundo é daqueles que sabem, com proficiência, ler e escrever. Em quase todas as práticas sociais somos convocados a demonstrar nossa competência leitora e também escritora. Um dos principais direitos adquiridos com a leitura é o de enxergar-se no mundo e nele atuar, tornar-se sujeito de fato em uma sociedade letrada, tomar parte nas decisões públicas e conscientizar-se de seu papel no mundo. É o que se pode confirmar em Silva (2005, p. 45): "Ler é, em última instância, não só uma ponte para a tomada de consciência, mas também um modo de existir no qual o indivíduo compreende e interpreta a expressão registrada pela escrita e passa a compreender-se no mundo".

Assim, o ensino da leitura não deve estar dissociado da realidade existente fora da escola. É preciso que professores alfabetizadores sejam mais do que meros orientadores técnicos. O ensino da leitura deve estar intimamente ligado ao mundo que cerca a escola e, principalmente, ao mundo dos alunos.

\section{Leitura de mundo}

Ao ensinar as primeiras letras e, por conseguinte, a leitura e a escrita, é preciso ligar o mundo dos alunos ao mundo escolar. Palavras e textos sem sentido para o aluno não o ajudam a adquirir a competência leitora e escritora. Sobre esse assunto, Freire (2009, p. 15) relata: "Fui alfabetizado no chão do quintal de minha casa, à sombra das mangueiras, com palavras do meu mundo e não do mundo maior dos meus pais. O chão foi meu quadro-negro; gravetos, o meu giz". 
Isso acontece porque, segundo o mesmo autor, a leitura de mundo acontece antes da leitura da palavra, isto é, as palavras que serão aprendidas pelos alunos já existem em suas ideias, em seus mundos, na forma oral, linguagem já adquirida pela criança nos primeiros anos de vida. A oralidade é uma das primeiras formas de comunicação da criança com o mundo que a cerca, com seus pais, irmãos, parentes e vizinhos. Ignorar as palavras já incorporadas na oralidade pela criança e que "A alfabetização é a criação ou a montagem da expressão escrita da expressão oral" (op.cit., p. 19) é no mínimo inocente, por descartar ferramentas pedagógicas importantes no processo de alfabetização. Um aluno dos primeiros anos escolares já possui toda uma vivência que deve ser valorizada no momento de sua alfabetização. Torna-se, então, desafio para o professor utilizar-se de mecanismos de ensino que privilegiem essa vivência. É o que podemos constatar em Lerner (2002, p. 17): "Ensinar a ler e escrever é um desafio que transcende amplamente a alfabetização em sentido estrito", sentido estrito aqui entendido como uma alfabetização voltada simplesmente à decifração do código.

Nota-se uma necessidade urgente de usar o mundo real como plataforma de ensino, fazendo da sala de aula um grande laboratório de realidades, trabalhando com textos utilizados no mundo real, com cuidado extremo na escolha destes, pois "O comando da leitura e da escrita se dá a partir de palavras e de temas significativos à experiência comum dos educandos e não de palavras e de temas apenas ligados à experiência do educador" (FREIRE, 2009, p. 29). O aluno, ao tomar contato com um texto escrito, precisa estabelecer relações mentais daquilo que está sendo lido com o que já possui arquivado em sua memória, movimento este que o dota da possibilidade de prever certas situações que podem ou não acontecer em seguida no texto, fazendo-o atribuir significado ao que está lendo. Tal possibilidade só se dará com a oferta de textos para este aluno.

Para construir significado ao ler, é fundamental ter constantes oportunidades de se enfronhar na cultura do escrito, de ir construindo expectativas acerca do que pode "dizer" neste ou naquele texto, de ir aumentando a competência linguística específica em relação à língua escrita [. . . ]. (LERNER, 2002, p. 40-41)

É preciso ofertar aos alunos textos variados, porém, selecionados entre aqueles que tenham uso corrente na sociedade e que desempenhem alguma 
função social, pois só assim se conseguirá que o aluno estabeleça relações com seu mundo, posto que ele está inserido e atuando na sociedade.

\section{Prática social da leitura}

A escola precisa, além de valorizar a vivência que a criança carrega ao adentrar aos seus portões, reconhecer a necessidade de minimizar ao máximo o fosso que se verifica entre leitura na e para a escola e a leitura existente como prática social, fora da escola. É preciso com urgência fazer com que a leitura praticada no cotidiano das pessoas passe a ser utilizada em sala de aula. Sobre este aspecto, Lerner (2002, p. 35) aponta que "A versão escolar da leitura e da escrita não deve afastar-se demasiado da versão social não-escolar".

Nesse momento, o professor é extremamente importante para que esse objetivo possa ser atingido, pois é a ele que cabe o papel de selecionar os textos que serão trabalhados em sala de aula. É seu papel a escolha de um bom livro didático, que traga material o mais próximo possível da realidade; é ele quem prepara as aulas e escolhe que ferramentas de ensino irá adotar. Assim, orienta Lerner (id. ib.), "É responsabilidade de cada professor prever atividades e intervenções que favoreçam a presença na sala de aula o objeto de conhecimento tal como foi socialmente produzido [...]".

Além da utilização de textos tais quais foram produzidos socialmente, é preciso também valorizar a vivência dos alunos e utilizar-se daquilo que está presente em seu mundo para ensiná-lo a ler e escrever, o que não significa limitarse ao mundo do estudante em formação. Quer dizer que o aluno apropriar-se-á mais facilmente da leitura e da escrita quando da utilização de palavras que fazem parte de seu cotidiano, sem que se negue a ele o contato com outros mundos e que possam ampliar seu conhecimento.

A escola tem o papel social de formar cidadãos plenos de direitos e capazes de atuar no mundo em que vivem. Desse modo, o ensino escolar da leitura deve passar pelos diversos textos que circulam na sociedade, no dia-a-dia das pessoas, e a escola precisa despojar-se de uma prática que assumiu durante muito tempo: a de ensinar a ler para ler. No dizer de Foucambert (1994, p. 10), "A escola deve ajudar a criança a tornar-se leitora dos textos que circulam no social e não limitála à leitura de um texto pedagógico, destinado apenas a ensiná-lo a ler". 
O ensino da leitura e da escrita assume, então, um papel social capaz de determinar o futuro daqueles que aprendem e dominam essas práticas. $\mathrm{O}$ não saber ler e escrever torna-se um fator de segregação social, pois aqueles que não possuem tais conhecimentos encontram-se marginalizados do mundo, enquanto os que os possuem são capazes de atuar de forma crítica.

\section{0 professor-alfabetizador}

Para a formação de alunos leitores é preciso que haja bons professoresalfabetizadores atuando neste nível de ensino, e que também sejam leitores. Outro ponto relevante é perceber que a atuação do professor, dentro e fora da sala de aula - não só como ele ministra suas aulas, mas também como é sua preparação para ministrá-las -, será determinante para o sucesso na formação de alunos leitores e escritores. Parece um tanto quanto absurdo um ser ensinar a outro aquilo de que não faz uso, que não pratica. Logo, parece indissociável do professor o ato de ler.

É preciso que o professor leia. Não somente em sala de aula para seus alunos, mas também para sua formação. E ler para a formação não se reduz a leituras teóricas, daquelas tidas como obrigatórias, mas sim de leituras prazerosas daquilo que melhor lhe cai: romances, contos, poesias, reportagens etc.. Para ensinar alguém a ler e a ter prazer em ler é preciso também encantar-se com essa prática: "[...] sem professores que leiam, que gostem de livros, que sintam prazer na leitura, muito dificilmente modificaremos a paisagem atual da leitura escolar". (SILVA, 1998, p. 22)

O professor que se coloca como exemplo para o aluno em sala de aula terá mais condições de fomentar os hábitos e o prazer pela leitura. Aquele que lê por gosto, por vontade, torna-se um leitor crítico com mais facilidade, pois é capaz de intervir sobre o que leu.

\section{Livros: cultura acumulada}

É principalmente por meio de livros que temos acesso à produção cultural de toda a humanidade, desde os tempos mais remotos aos dias atuais - esse acesso é 
um direito de todos nós. Dentre todos os benefícios que a leitura traz ao indivíduo, aqui mencionados, esse não poderia ficar de fora.

O homem difere dos demais animais principalmente pela capacidade de comunicar e transmitir, de geração a geração, a sua cultura. Com o advento da escrita, o homem encontrou o meio privilegiado para propagar os conhecimentos que foi adquirindo com o passar do tempo. Desde a Modernidade, a escola constitui o lugar propício para propagação da cultura humana acumulada, tornando-se a leitura parte indissociável do mundo escolar, em conformidade com o que diz Silva (2005, p. 31): "Em verdade, seria difícil conceber uma escola onde o ato de ler não estivesse presente - isto ocorre porque o patrimônio histórico, cultural e científico da humanidade se encontra fixado em diferentes tipos de livros".

Para fazer da escola um lugar de formação de leitores é preciso equipá-la com livros, salas e cantinhos de leitura, bibliotecas. Livros de assuntos variados e capazes de agradar os diversos tipos de leitores, que propiciem a estes uma gama de conhecimentos tal que seu repertório verse sobre vários temas. "O leitor assíduo e dedicado vai tomando posse da herança humana que se transmite através do livro. Quem muito lê vai reunindo em si mais lembranças e conhecimentos do que se tivesse mil anos de idade" (PERISSÉ, 1998, p. 26). O hábito da leitura é capaz de transformar o leitor: à medida que ele vai tomando posse dos conhecimentos presentes nos livros, estes conhecimentos vão se agregando a sua essência, transformando-o em outro ser, diferente do que era antes da leitura. Isto porque, quando uma leitura é feita de modo consciente e o leitor se coloca de forma aberta para o que é lido, o conteúdo da leitura se agrega a ele, passando a fazer parte dele. A esse respeito, Perissé (op.cit., p. 22) observa que "A arte de ler bem gera em nós, com o tempo, uma segunda natureza. Ao nosso "eu" acrescentam-se e mesclam-se contribuições vivas de outras cabeças e corações humanos".

\section{Considerações finais}

A discussão acerca da importância da leitura nos processos de alfabetização das crianças aqui realizada não pretende fechar o assunto. Ao contrário, quer justamente instaurar em professores-alfabetizadores o desejo de melhorar sua prática e, consequentemente, o de buscar respostas às suas próprias inquietações. Parece-nos salutar o debate sobre a necessidade de se extinguir das escolas uma 
alfabetização que prioriza apenas a decifração dos signos linguísticos usados na escrita, trocando-a por uma prática que valorize a vivência dos alunos e tudo o que eles já carregam na oralidade, para, assim, ajudá-lo a transpor mais facilmente o que já existe na ideia para o mundo da escrita.

Entendemos que o professor representa um exemplo para seus alunos, que tendem a vê-lo como modelo. Assim, um professor que não lê dificilmente poderá formar alunos leitores. A leitura precisa tornar-se um hábito dentro e fora da escola, para professores e alunos. À escola cabe propiciar espaços e momentos de leitura para alunos e professores; salas de aulas devem estar recheadas de livros, e as unidades escolares, de espaços os mais diversos de fomento à leitura, locais em que alunos e professores sintam-se motivados a ler.

Somente com o empenho de todos os envolvidos no processo educativo, principalmente no momento da aquisição da leitura e da escrita, é que poderemos vislumbrar uma nova escola, na qual de fato formem-se leitores.

\section{Referências}

FOUCAMBERT, Jean. A leitura em questão. Tradução: Bruno Charles Magne. Porto Alegre: Artes Médicas, 1994.

FREIRE, Paulo. A importância do ato de ler em três artigos que se completam. $50^{\mathrm{a}}$ ed., São Paulo: Cortez, 2009.

LERNER, Délia. Ler e escrever na escola: o real, o possível e o necessário. Tradução: Ernani Rosa. Porto Alegre: Artmed, 2002.

PERISSÉ, Gabriel. Ler, pensar e escrever. 2a ed., São Paulo: Arte \& Ciência, 1998.

SILVA, Ezequiel Theodoro da. Elementos de pedagogia da leitura. São Paulo: Martins Fontes, 1998.

$O$ ato de ler: fundamentos psicológicos para uma nova pedagogia da leitura. São Paulo: Cortez, 2005.

recebido em 11 jan. 2012 / aprovado em 10 ago. 2012

Para referenciar este texto:

PELEGRINI, A. Leitura: uma necessidade para alunos e professores. Dialogia, São Paulo, n. 16, p. 199-206, 2012. 